\title{
The Strength of the Euro - Challenges for ECB Monetary Policy
}

\author{
Ansgar Belke ${ }^{1}$ \\ ${ }^{1}$ University of Duisburg-Essen, Monetary Experts Panel European Parliament and IZA Bonn, Germany \\ Correspondence: Prof. Dr. Ansgar Belke, University of Duisburg-Essen, Monetary Experts Panel European \\ Parliament and IZA Bonn, Germany. E-mail: ansbel@aol.com
}

Received: November 11, 2014

Accepted: December 4, 2014

Online Published: January 4, 2015

doi:10.5430/rwe.v6n1p72

URL: http://dx.doi.org/10.5430/rwe.v6n1p72

This paper is heavily based on a Briefing paper prepared by the author for presentation at the Committee on Economic and Monetary Affairs of the European Parliament for the quarterly dialogue with the President of the European Central Bank, July 2014, Brussels.

\begin{abstract}
This paper comments on the main challenges stemming from the strong Euro for ECB monetary policy. For this purpose, it starts with a detailed analysis of the current macroeconomic background and the related statements by ECB President Mario Draghi during the three most recent press conferences at the event of the monthly ECB Governing Council meetings. It then deals with a couple of challenges relating to the question whether the ECB should gear its unconventional monetary policies towards the Euro exchange rate.

Does exchange rate orientation of monetary policy represent a violation of the ECB's mandate? Searching for the exchange rate benchmark: what exactly is the equilibrium rate to target? Influencing the euro's real exchange rate through changes of the nominal rate: will markets be invited speculate about the ECB's "Euro bottomline"? Don't devaluations through unconventional monetary policies prevent necessary structural adjustment - because structural reforms more effective than devaluations? What are the driving forces behind the request for a Euro devaluation one-sided political interests? How to cope with the ineffectiveness of devaluations to fight a business cycle trough, denoted by the so-called J-curve effect?

In its final part, the paper dwells extensively on the potential effects of envisaged Quantitative Easing on current and expected interest rates in the Eurozone and thus finally via the asset portfolio channel also on the external value of the euro.
\end{abstract}

Keywords: Euro, European Central Bank, quantitative easing, exchange rate fundamentals

"Over the last few days we received plenty of advice from political figures, from institutions and, almost every day now, ... on exchange rates ... . So we are certainly thankful for this advice and certainly respect the views of all these people. But we are, by the Treaty, we are independent. So people should be aware that if this might be seen as a threat to our independence, it could cause long-term damage to our credibility."

Mario Draghi (2014), during the ECB's press conference on May 8 in Brussels

\section{Introduction}

The euro's steady rise represented one of the market surprises during the first part of the current year. Since the beginning of 2014, the Euro has appreciated both against the dollar and - much less - also in trade-weighted terms. At around USD1.40, the Euro has in the meantime been at its strongest value against the dollar since late 2011 (Figure 1). However, the politically important USD/EUR exchange rate has by far not reached its record value reached in 2008. (Note 1) Within one year it increased from USD1.28 to USD1.39. It has, however, gone down again by about four cents in the recent weeks. ECB President Mario Draghi thus seems to have been partially and maybe temporarily effective in "talking down the euro" in his monthly press conferences after the ECB Council Meetings (Draghi, 2014a,b). 
The main purpose of the paper is (a) to discuss the challenges for ECB monetary policy stemming from the sharp rise of the euro in the context of a nascent euro area recovery and (b) to assess the Euro exchange rate impact of the envisaged Quantitative Easing $(\mathrm{QE})$ in this respect.

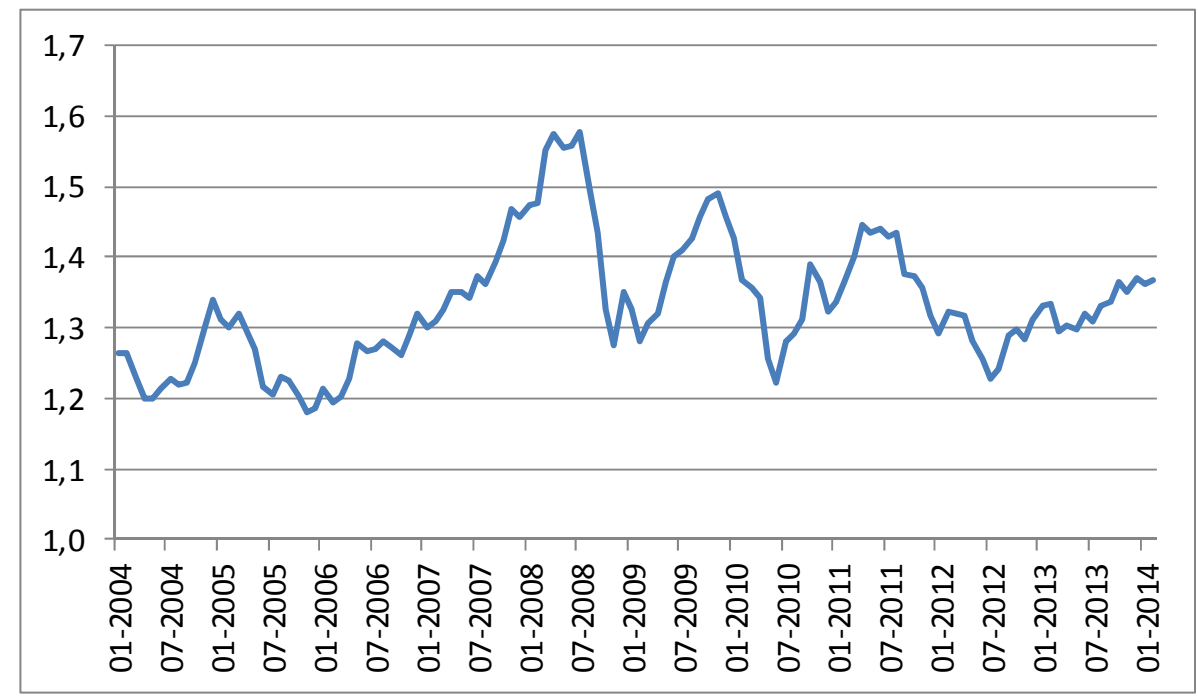

Figure 1. USD/EUR exchange rate, nominal since 2004

Source: Bank for International Settlements, Web: http://www.bis.org/statistics.

The USD-EUR exchange rate remained rather stable during the first half of 2013, after having experienced a positive trend during the second part of 2012. Subsequently, a steady, but relatively small appreciation against the USD took place (see Figure 2), and even the recent maximum of 1.39 being still within the confidence bands around purchasing power parity (PPP) rate.

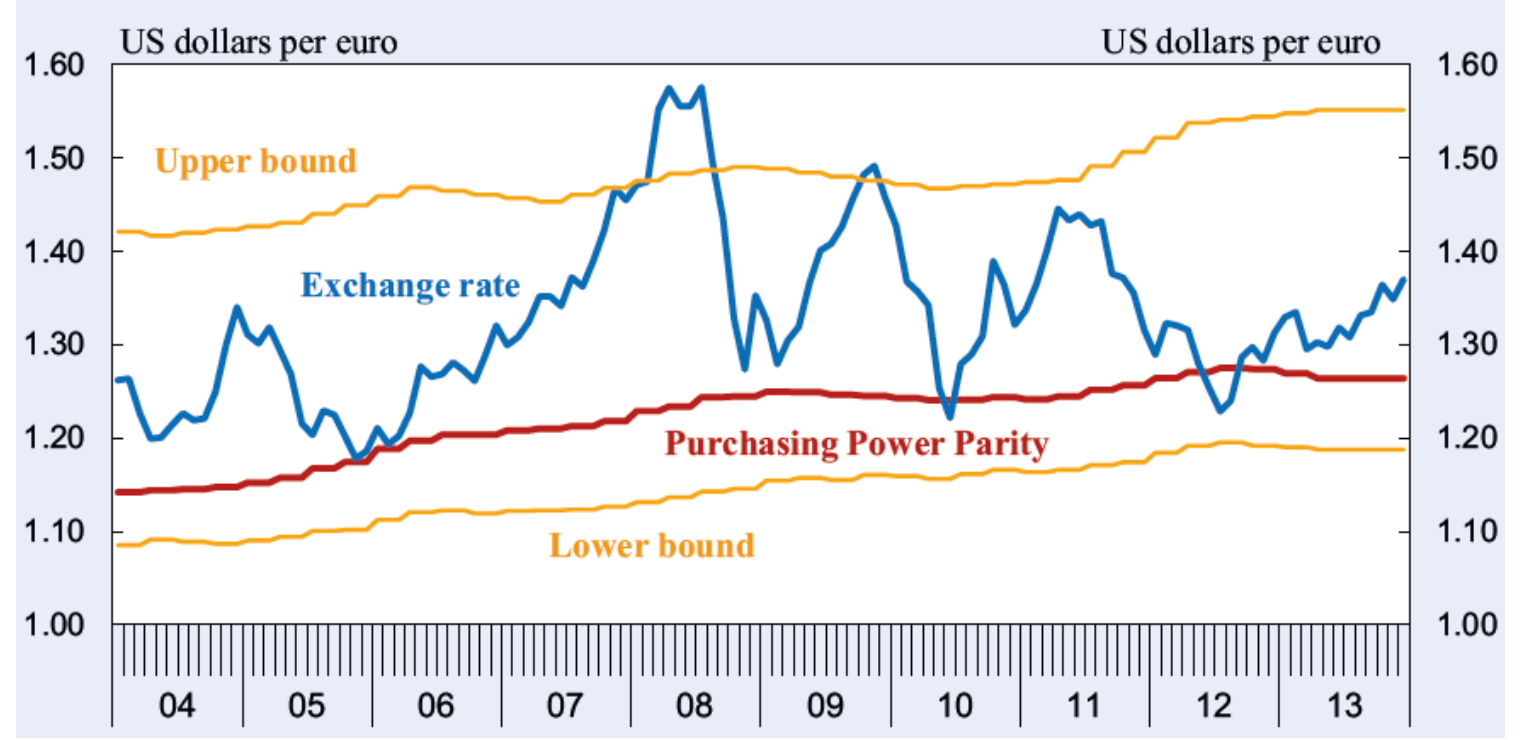

Figure 2. Exchange rate of the Euro against the US dollar and PPP

Source: EEAG, 2014 (p.34 a) based on ECB and OECD data. The nominal exchange rate is based on monthly data, while the exchange rate based on purchasing power parity (PPP) is given at a quarterly frequency. The PPP upper bound represents the 75th percentile of the euro country-specific PPP estimates vis-à-vis the US dollar; the lower bound the 25th percentile. The US dollar-euro PPP rate is calculated as the GDP-weighted average of the euro country-specific PPP estimates vis-à-vis the US dollar. 
The consensus view at the start of 2014 was that the economic recovery in the United States would exert upward pressure on the USD. The extremely low level of current and also of expected short-term interest rates implanted in the markets through Mario Draghi's forward guidance have also been expected to weaken the euro. But the Euro has, on the contrary, continued to appreciate, a trend which may, among others, reflect the current Eurozone account surpluses and the improving investor confidence that the Eurozone debt crisis is overcome: "Incidentally, one of the reasons for the strength of the exchange rate was the inflows coming from outside from investors interested in Eurozone economies, and that has moderated quite so in the last quarter" (Draghi, 2014). By lowering the prices of imports, which are costs for inputs to domestic production, the euro's appreciation has also led to subdued price pressures. (Note 2) Only this aspect of the Euro strength has been emphasized mantra-like a multitude of times by ECB officials.

The remainder of the paper is organised as follows. Section 2 discusses, mainly based on own research conducted by the author of this paper, the main challenges for ECB monetary policy stemming from the sharp rise of the Euro in the context of a nascent Eurozone recovery. Section 3 finally concludes.

\section{The Strong Euro: Main Challenges for ECB Monetary Policy}

\subsection{Macroeconomic Background}

The challenges of the strong euro for the ECB's monetary policy are currently discussed in a macroeconomic environment of well explained lower inflation - regaining competitiveness of the Eurozone's South and necessary ongoing deleveraging processes nearly everywhere in the Eurozone (Note 3) - and slightly improved growth projections for the Eurozone. This is mirrored by some disinflation going on: current and anticipated inflation are well below the ECB's target of slightly below 2 percent HICP inflation. The ECB should not act against this well-explained disinflation. Instead, still negative loan growth in Italy, Spain or Portugal due to bad loans on the banks' balance sheets and to the upcoming bank stress test and the emanating new monetary policy driven bubbles on the bond and stock markets weigh much more heavily (Belke and Verheyen, 2014).

Over the last months, hence, the impression emerged among analysts that the most recent unconventional ECB policy measures have clearly aimed at a sustained Euro devaluation (Jolly and Alderman, 2014) because all other monetary policy transmission mechanisms to revive economic activity especially at the small and medium-sized enterprise (SME) level in the South of the Eurozone and thus to induce a positive inflation stimulus are more or less distorted.

The argument runs as follows: whereas in the period before, falling energy and food prices and climate factors have been relevant, this has changed significantly in the more recent past. The strong Euro has become a significant driver of increasingly lower inflation rates in the Eurozone (Draghi, 2014). This is especially valid because the Eurozone economy is more open than the US one (Belke and Gros, 2002). Hence, with an eye on its mid-term price stability target of below but close to 2 percentage points HVPI inflation, the ECB has to act - but in close correspondence with the prohibition not to directly follow an exchange rate target. According to Mario Draghi (2014): "If we go back to the last three years, we have two stories. First, the first half of the last three years, it was mostly the declines in the price of oil and food and perhaps some other commodities that have accounted for something like $75 \%, 80 \%$ of the difference between inflation then and inflation now. Then, in the last year, it was the prices in dollar terms haven't moved much; it was the exchange rate that has accounted for the decline in inflation".

In order make sure that a deflation scenario or, at least, a medium-run deviation of inflation from its target, can be avoided in the Eurozone, further unconventional monetary policies could well be geared towards the Euro exchange rate (Draghi, 2014a,b). In this vein, policy measures such as Quantitative easing $(\mathrm{QE})$ could be seen as an insurance against deflation. (Note 4 )

On the deflation fears: one at first glance disturbing fact is that ECB President Mario Draghi in his most recent ECB press conference as of 5 June 2014, surprisingly argued that he does not see a danger of deflation right now (Draghi, 2014). However, if one reads Mario Draghi's statements during the ECB's press conferences more carefully, the argument appears to be of a strikingly different substance: already very low positive inflation rates, not necessarily deflation, he argues, make the necessary reduction of public debt in over-indebted Eurozone member countries more difficult. This is because more real resources have to be expended for the necessary cutback of public debt in view of disappointing growth figures for countries such as Italy and, above all, France.

This is nothing else than the explicit return of the idea of financial repression in Europe (Reinhart, 2012). According to calculations of Laurence Boone (Bank of America Merrill Lynch) the French debt-to-GDP ratio may climb beyond the 100 percent threshold already next year and to 105 percent until 2018. The situation in Italy appears even 
more drastic in this context. In this country the debt-to-GDP ratio could even develop towards 150 percent in the coming years (Eckert and Zschaepitz, 2014).

Among both arguments in favour of increasing expected inflation through weakening the Euro brought forward by Mario Draghi - prevention of deflation and alleviating the cutback of debt - the second one seems to be by far the more relevant one. This is because (as frequently stated even by ECB officials) there is currently neither incidence of current deflation nor a significant danger of future deflation in the Eurozone - with deflation defined as a permanent fall in prices dampening aggregate demand because consumers would defer purchases while waiting for prices to fall further in the future. At the level of individual goods in the Eurozone, one usually finds a number of goods where prices have actually been falling, but one finds only scarce evidence for related declines in demand (and sometimes even the contrary). Hence, the widespread concerns about deflation impairing aggregate consumption seem to be due to a lack of a sound microeconomic foundation.

Accordingly, the ground for the ECB's unconventional monetary policy measures announced after the ECB Council's June Meeting was already laid by Mario Draghi's statement at the ECB's press conference on May 8 in Brussels: "It's true that the recovery is proceeding, but it's proceeding at a slow pace and it still remains fairly modest. And there are some downward risks now, and the risks have to do with the possible weakening of global demand, have to do with geo-political risks that are of serious significance and have to do with the exchange rate".

We now proceed with an assessment of the main arguments in favour or against efforts by the ECB to weaken the euro. We start from the basic insight that the relevant variable for expenditure switching in any serious macro model is not the nominal but the real exchange rate. But there is no evidence that any central bank is really able to sustainably influence the real exchange rate - the de facto relevant variable. On the contrary, in the short run any manipulation of the nominal exchange rate bears the character of a "beggar-thy-neighbour" policy. And, as shown above, the consequences of the exchange rate moves so far do not make a case for "market failure" which could be the only reason for central bank intervention (Belke, 2013).

\subsection{Does Exchange Rate Orientation of Monetary Policy Represent a Violation of the ECB's Mandate?}

Exchange rate orientation of monetary policy does not represent a violation of the ECB's mandate - as long it is not understood as a direct exchange rate target and considerations run along the second pillar of the ECB's strategy. Accordingly, Mario Draghi (2014) strongly argues that a strong Euro is a serious concern for the ECB, even it does not have any target: "I've often said the exchange rate is not a policy target, but it's very important for price stability and growth. And I think we've discussed on other occasions how the current level of inflation has been impacted by the appreciation of the exchange rate". (Note 5)

\subsection{Searching for the Exchange Rate Benchmark: What Exactly Is the Equilibrium Rate to Target?}

In order to be legitimised to give a statement like "the euro is too strong" one should have an exact well-founded benchmark, an estimate of the equilibrium exchange rate which serves to reach the ECB's HICP inflation target of close to 2 percent, in mind. Optimally, the latter is based on scientific evidence and is, as usual, derived from purchasing power or unit labour cost parity considerations. But you can think of nearly no more controversial issue in international macroeconomics than determining whether observed exchange rate swings are persistent deviations from a given equilibrium or whether the equilibrium rate itself has moved and exhibited a structural break or even whether the equilibrium rate is path-dependent (Krugman and Obstfeld and Melitz, 2012, pp. 350ff.).

What factors lie behind the appreciation of the euro? Usually, a significantly lower external value of the Euro should have been expected with an eye on the Fed's announcements of potential exit from unconventional monetary policies and on the amount of still unresolved structural issues in the Eurozone which can by definition not be resolved by the monetary authority (Belke, 2013). Some analysts try to explain the euro's rather strong performance by pointing at the ECB's balance sheets which have been in the process of shrinking relative to the Fed's and the BoE's ones - at least before the new targeted LTROs (TLTROs) have been announced after the June ECB Council Meeting. Moreover, the Eurozone's significant current account surplus, capital inflows into the South of the Eurozone, at times falling yields of dollar bonds and shrinking amounts of dollar trades by Eurozone MFIs may have played their role as well.

Most importantly, a common equilibrium exchange rate for the Eurozone as a whole as, for instance, vis-à-vis the US-dollar (which results in the politically most important USD/EUR exchange rate) does not exist. The Euro currently appears too strong for a couple of Southern Eurozone countries. At the same time, however, it appears too weak for some Northern Eurozone countries such as Germany. This implies that a further fall of the external value of the Euro would lead to windfall gains for a country which already is in a better economic shape. 
Belke, Goecke and Guenther [2013, based on a more complex hysteresis-based algorithm] and more recently, also Morgan Stanley's Hans Redeker [based on a simple unit labour cost calculus] came up with some estimates of exchange rate pain thresholds of the USD/EUR exchange rate and a corresponding ranking of Eurozone countries: Germany is able to sustain 1.54 dollar-per-euro, whereas the Spanish exchange rate pain threshold amounts to 1.29 dollar, the Finnish one to 1.28 , the French one to 1.23 dollar, the Italian one to 1.19 dollar and the Greek one already to 1.04 dollar. The estimate for Germany, for instance, is surprisingly close to the 1.55 dollar-per-euro calculated by Belke and Goecke and Guenther, 2013.

In summary, these studies conclude that there is no unique USD/EUR exchange rate to target in order to revive the Eurozone economy in order to avoid deflation and bring medium-run expected inflation back to close to 2 percent the exchange rate pain threshold is path-dependent and Eurozone member country-specific (whereas the ECB is obliged to enact its policies with an eye on the Eurozone as a whole).

"What is more, economic literature has often detected destabilising effects from intervention. Intervening within a narrow band of the equilibrium rate is likely to increase the chances of creating persistent instability. Unfortunately, the likelihood of meeting equilibrium is relatively remote. Experience shows that intervention increases the probability of stability only when the rate is clearly misaligned. An additional, and perhaps more striking argument against intervention, is that the factors driving the direction and intensity of exchange rate moves - that is, for instance, expected growth and capital returns - are beyond the reach of monetary policy: apart from the price level it is hard to see how monetary policy can have a systematic impact on the variables which are usually held responsible for exchange rate levels" (Belke and Koesters, 2004).

In addition, the established relation between the exchange rate and its fundamental drivers itself appears to be highly distorted by unconventional monetary policies of the world's leading central banks - in the same way as the latter have become the dominant drivers of stock markets all around the globe. So it is not at all surprising that the usual suspects such as the interest rate parity cannot explain the - relative to the shaky grounds of recovery and, as admitted by Mario Draghi himself, lack of structural reforms - high external value of the Euro in the short- to medium run.

Finally, in order to influence the exchange rate permanently, one would be in need of reiterating interventions. But direct forex interventions - if non-hidden or detected and laid open by market participants - are politically costly. Hence, there is an incentive for central banks to disguise their grip on the exchange rate. But markets have in the meantime already conjectured that the ECB's unconventional monetary policies are geared towards the exchange rate (Belke and Gros, 2014). According to Jolly, Alderman and Bray (2014) and many others: "Taken together, ... the measures announced Thursday are aimed at the exchange rate, as the biggest problem the E.C.B. really faces is the strength of the euro. The Federal Reserve, the Bank of England and the Bank of Japan all set out deliberately to weaken their national currencies ... and now the European Central Bank "is catching up." These are strong hints that there is more in the ECB's "exchange rate policies" than mere domestic orientation based on the second pillar of the ECB's monetary policy strategy: it is characterised by international monetary policy interaction and thus may even represent a step within an international "devaluation game" (Taylor, 2013).

Hence, taking all this in a nutshell, it does not come as a surprise that Mario Draghi multiple times stated that the Euro exchange rate is not a policy target in itself. But if asked to comment whether the ECB "Governing Council has some kind of a trigger point where the euro exchange rate is too strong, prompting the bank to act in the future" he just answers "No, we don't have a trigger. We just see that this is having the effect of basically depressing further the inflation rate. Again, if you take that comparison I made with the first quarter 2012, there are actually two stages. One is in fact when energy prices and food prices had the effect of depressing the rate of inflation. That is not, in fact, as continued beyond, I think, mid-2013. After that, the contribution of energy prices and food prices is not really important. And it's actually the exchange rate that keeps the inflation rate low and depressed. The exchange rate, both nominal and effective, has appreciated by something like 10 percent since mid-2012 to today", (Draghi, 2014a).

Markets are thus left alone with their answer to the question why and how the ECB should affect the euro's external value if the impact of the exchange rate on the Euro inflation varies strongly over time and, at the same time, it is not clear what the exchange rate compatible with the Eurozone's target inflation is: "In this sense, we do not link our medium-term assessment to a precise level of the exchange rate" (Draghi, 2014a). It thus directly follows from its medium-term strategy that the ECB should not have any reason to try to influence the Euro exchange rate! 


\subsection{Influencing the Euro's Real Exchange Rate through Changes of the Nominal Rate - Searching for the "Euro Bottomline"}

There are serious doubts that it really makes sense to apply direct or indirect exchange rate policy to compensate for the Eurozone-specific bad growth performance. This is because high (youth) unemployment in some of the Eurozone member countries bears a structural character. Beyond significant fine-tuning problems (including coping with a variety of feedback effects and country- or even region-specific exchange rate pain thresholds) and of a controlled implementation of a devaluation via expansionary unconventional monetary policies one has to consider that wage-negotiating parties do traditionally not subordinate "themselves to indirect reductions of their real wages via devaluations of the home currency" (Belke et al., 2004).

If, additionally, imported inflation leads to higher wage demands (and this may even be intended by the ECB because this tends to cause increase inflation figures), the prospects for unemployment in the Eurozone, but especially in the South of the currency union, become even worse (Belke et al., 2004). A multitude of studies has shown that a (too?) strong focus has been put on public budget and debt consolidation as compared to increasing international competitiveness (Gros et al., 2014). If at all, the benefits of a weaker Euro should consist of enhancing international competitiveness of the Eurozone's problem countries. If, in turn, these benefits are eradicated by higher wage growth, weakening the Euro does not make much sense. This is especially so because a spiral of devaluations and wage increases and, thus, an unforeseeable variability of and uncertainty about the Euro exchange rate will be unavoidable consequences in that case. This scenario frequently coincides "with periods of excessive speculation which have the potential to harm the economy because the speculation waves hamper a sound calculation by the export oriented firms" (Belke et al., 2004).

Hence, any exchange rate policy which is backed by discretionary unconventional monetary policy runs the risk of triggering additional destabilizing real effects and of durably modifying the functioning and the dynamics of the economy. Already now, most of the common fundamentals based asset price models for sovereign bonds or stocks cannot be used anymore because they are dominated by discretionary ECB interventions. From this perspective, it cannot be excluded that the most recent Euro appreciation "was largely determined by speculation about the future ECB policy itself. The markets seem to be willing to test the "bottom line" of the central bank: Does the ECB intervene at rate of $1.30,1.40$ or 1.50 " (Belke et al., 2004)? A credible ECB commitment not to directly or indirectly target the exchange rate with its current and future unconventional monetary policy measures (or even to intervene in the FX market) would probably be the best measure to calm down the foreign exchange markets and to stop the upward trend of the Euro (Belke et al., 2004).

\subsection{Devaluations through Unconventional Monetary Policies Prevent Necessary Structural Adjustment}

"Devaluations of the home currency induced by monetary policy tend to prevent or at least contribute to a delay of necessary structural adjustments in the Eurozone. A massive devaluation initially improves the international price competitiveness significantly but renders product and process innovations a less pressing issue than without the devaluation. Moreover, there is no sufficient pressure any more towards structural adjustment on labour and product markets", (Belke et al., 2004). With an eye on the structural character of unemployment in some parts of the Eurozone this seems to be a quite important caveat (see Section 2.4). "In contrast, the credible absence of interventions or of a monetary policy geared to the exchange rate forces entrepreneurs and politicians to enact the necessary adjustments", (Belke et al., 2004).

This is a rather important point since evidence shows that declining credit growth in some parts of the Eurozone is not a supply but a demand problem (see Section 2.1). "Especially in the case of negative supply shocks, one should refrain from accommodating devaluations which at best alleviate the short term symptoms of low growth in Europe. Pro-active devaluations significantly lower the incentives to break open encrusted structures on labour and product markets and, thus, prospects for growth and employment", (Belke et al., 2004).

\subsection{Structural Reforms More Effective than Devaluations}

It has often been argued that a lack of international competitiveness stemming from labour and product market sclerosis combined with low productivity can be compensated much easier "if the necessary macroeconomic adjustment takes place via the exchange rate than through wages. From this perspective, the devaluation of the Euro may represent a substitute for wage restraint and structural reforms", (Belke, Herz and Vogel, 2006 or Belke et al., 2004). "However, there are some pieces of evidence available from history which proves exactly the contrary. For instance, it is by now clear that the positive employment impacts without additional inflation claimed for the UK and Italy after their exit from the European Monetary System (EMS) in 1992 cannot be traced back to the massive 
devaluations of the respective currencies. Rather, these effects were induced by policy reforms which took effect simultaneously with the exit of the Italian lira and the British pound from the EMS. Hence, in empirical studies investigating the efficiency of exchange rate movements in terms of employment, the extent of reform has to be modelled as an explaining variable which is endogenous with regard to the choice of the exchange rate system. Then it may become clear that structural reforms and not, as often maintained, pro-active devaluations of the respective home currency are the most efficient way towards more growth and employment. Hence, the Euro exchange rate cannot be regarded as an important short-term oriented instrument to prevent path-dependence in unemployment in the presence of negative shocks" (Belke et al., 2004).

Further arguments speaking against exchange rate policies relate to the fact that demand for Eurozone exports is relatively inelastic to exchange rate movements and that exchange rate volatility induced by the ECB's unconventional monetary policies or even interventions may have damaging effects on the real economy (Belke et al., 2004). If, however, exchange rate movements are not driven by labour and/or goods market shocks but instead by policy fine-tuning and dirty floating of the Euro exchange rate, they tend to cause additional real economy problems instead of alleviating labour and goods market sclerosis (Belke and Gros, 2002, and Belke et al., 2004).

\subsection{One-sided Political Interests? Driving Forces behind the Pressure for Euro Devaluation}

The ECB's focus on the too strong Euro is strengthened at a time when, for instance, the French government is pushing for a wider interpretation of the SGP and weakening the euro, given its despair due to worsening international competitiveness and increasingly bad growth forecasts for this country which, in turn, lets it fail the public deficit target also in 2015, although the EU Commission allowed a prolongation of the fulfilling period of deficit target for the third time now. Softening the SGP does not seem to be enforceable since beyond some Northern countries also the former and current programme countries would clearly not accept this. Lowering the external value of the home currency in this type of politico-economic constellations has so often in history been the remaining valve to cope with structural issues. Correspondingly, the respective countries enforced some pressure to weaken the Euro on the ECB. However, Mario Draghi (2014a) delivers a well-balanced and impressive assessment of these activities, after a journalist asked him: "We are hearing more and more complaints from Paris about the strength of the euro. Would you like to respond to them at all?". He argues that these kind of testimonies with respect to the strength of the Euro may seriously threaten the ECB's independence and credibility. In detail he answered: "To the ... question, I would say that ... we received plenty of advice from political figures, from institutions and, almost every day now, on interest rates, on exchange rate s... . So we are certainly thankful for this advice and certainly respect the views of all these people. But we are, by the Treaty, we are independent. So people should be aware that if this might be seen as a threat to our independence, it could cause long-term damage to our credibility".

This example is only part of a more general (legitimacy and equal representation) problem. "The stylised fact that currency depreciations tend to have only a small direct macroeconomic impact on growth and employment in the export branch and may even be counter-productive in the medium and the long run, is supported by the mainstream of economists but is stubbornly rejected by some industry representatives. The latter often speak out in favour of a devaluation policy probably because they expect a group-specific net gain from this devaluation. By this, the determination of exchange rates and, thus, also a significant part of the exchange rate variance come under the influence of political-economic considerations" (Belke et al., 2004). Also from this point of view, it becomes quite clear that exchange rates these days tend to "represent more a policy instrument than a shock-absorber. This rather unambiguous public choice assessment involves the danger of not calculable fine-tuning the exchange rate by monetary policy which tends to destabilise expectations and to deter investors instead of attracting them. Hence, policy is well-advised to credibly voice its opposition against "manipulations" of the Euro exchange rate", (Belke et al., 2004).

\subsection{Devaluations Ineffective in Fighting a Business Cycle Trough}

The so-called J-curve effect makes devaluations of the home currency more difficult in terms of spot timing of the inflationary impulse (Krugmann, Obstfeld and Melitz, 2012, pp. 477ff.). This is especially so because the ECB's medium-term inflation projections for 2016 point at a recovery of HICP figures to values of at least 1.5 percent and the alleged "disinflation (not to speak of a deflation) problem" is thus relevant only in the short- to medium run. This is exactly the period for which the J-curve effect is valid.

"It is sometimes observed that a country's current account worsens immediately after a real currency depreciation and begins to improve only some months later because most import and export orders are placed several months in advance. Basically, these are decisions made on the basis on the previous exchange rate level. The primary effect of the depreciation is to raise the value of the pre-contracted level of imports in terms of domestic products", (Belke et 
al., essentially the price effect intended by the ECB through its measures adopted in June 2014]. Eurozone prices are automatically impacted by a Euro depreciation since import prices increase and production inputs become more expensive. In the short run there is nothing monetary policy can (and, in case of the ECB, wants) do to offset this effect which per se goes along with a negative impact on the current account, measured in the home currency. However, this increase in import prices (which may also feed through to consumer prices) is merely a valuation effect which is necessary but not at all sufficient to revive the economy in real terms through an improvement of the current account (which is already increasingly positive for the Eurozone on the whole as opposed to that of some specific member countries).

"How significant this mechanical pass-through effect is for the Eurozone is difficult to assess ex ante because it depends on the degree to which Eurozone imports are denominated in other currencies than the Euro and it is not known on a solid empirical basis up to now what share of Eurozone imports is denominated in euro. Nevertheless, it can be argued that more than 20 percent of world trade is denominated in euros and that, above all, countries not belonging to but geographically close to the Eurozone like the Central and Eastern European countries denominate their exports to the Eurozone in euros. Hence, the USD/EUR exchange rate remains relevant for Eurozone imports. However, neither the exact time pattern of the expansionary effect, nor the resulting net expansionary effect can be calculated and forecasted exactly", (Belke et al., 2004). Maybe the ECB knows better and has implemented "close to reality" calibrated values in its DSGE models. It thus cannot be ruled out that "the expansionary impact takes effect even at an inopportune moment, namely not earlier than after the recession has been overcome" (Belke et al., 2004).

For the majority of industrialised countries, a J-curve lasting between six months and one year turns out to be a precise estimate. It is not a remote possibility that monetary expansion can thus even depress output initially by depreciating the home currency. It thus may take some time before any type of unconventional monetary policy may cause an improvement of the current account and higher demand for Eurozone products or services. "It may even be the case that the price increase of imports induced by the Euro revaluation harms the economy to a larger extent than the resulting export increase benefits it. Even from this perspective, a positive real economic net effect of a Euro devaluation strategy is more than doubtful" (Belke et al., 2004).

In summary, there will be no significant export-led employment gains by a devaluation of the euro. "As ever, it is still a valid presumption that employment problems can only be solved with an eye on the structural roots of these problems by structural reforms and not by changes in monetary variables" (Belke et al., 2004). Our main argument has also been strongly backed at least by the good performance of the German stock market DAX which has, in spite of the euro's appreciation, not followed the arguments brought forward by the Euro pessimists. Instead, avoiding a more pessimistic scenario for Eurozone growth and, thus, also for inflation figures due to a "too strong euro" is a challenge to the flexibility of Eurozone entrepreneurs and unions and also to the tolerance vis-à-vis deleveraging needs, but not primarily for the ECB. The ECB anyway cannot do too much against the relatively strong Euro and the relatively weak dollar since the latter may have its main origin in the US - the intended dollar weakness is driving the Euro up - and not only in the Eurozone as shown above. Hence, the most recent verbal interventions by Mario Draghi will probably only be able to slow down the appreciation of the Euro but not to stop it (Belke et al., 2004).

\section{The Euro Exchange Rate and Quantitative Easing}

As stated at the beginning, the ECB may aim at a sustained Euro devaluation, because all other transmission mechanisms are more or less distorted. As indicated in Mario Draghi's most recent press conference in June 2014, one option to achieve this may be QE. QE probably has lower political costs than explicit foreign exchange market interventions by the ECB. Exactly for this reason, explicit ECB FOREX market interventions have taken place only very rarely, for instance at the start of the previous decade.

Standard textbooks such as Krugman, Obstfeld and Melitz (2012, pp. 350ff.) would tend to argue that QE in the Eurozone, understood as lowering domestic interest rates even further, would most probably lead to a depreciation of the euro. But through what channels? How to deal with its impact on bond and asset prices in exchange rate portfolio models etc.? Unfortunately, the scientific literature on QE and its exchange rate effects is still in its infancy. Hence, we have to limit ourselves to bring forward some casual observations and thoughts in the following.

But the recent experiences with QE conducted by the Fed, BoE and Bank of Japan reveal that the exchange rate effects of these policies are generally ambiguous. With respect to the success of QE in the EU Nobel prize winner Joseph Stiglitz said recently at the World Economic Forum in Jordan: “... the evidence that it provided much stimulus to the economy is very weak. ... It may have contributed to asset price bubbles, it may have contributed a little bit to the weaker dollar, which actually helps US exports". (Note 6) Earlier, in 2010, Stiglitz has been 
dismissing the Federal Reserve's quantitative easing even as a "beggar-thy-neighbour" strategy of currency devaluation: "President Obama has rightly said that the whole world will benefit if the U.S. grows, but what he forgot to mention is ... that competitive devaluation is a form of growth that comes at the expense of others. ... So I think it is likely to present problems for the global economy going forward". From this perspective, QE in the Eurozone would merely imply the next step in a "currency war" whose effects are not at all necessarily positive for world and especially Eurozone growth which in turn may dampen the inflation-enhancing effect of QE. The latter is, according to non-official sources, estimated by the ECB to lie in between 0.2 to 0.8 percent HICP inflation per 1000 bn EUR QE per year (corresponding with about 80 bn. EUR per month) (FAZ, 2014).

So when to expect QE taking place in the Eurozone as well? It should be clear also to the ECB Governing Council that one should not implement QE before the Eurozone's banks will be cleaned up, because QE changes the values of assets and makes the determination of capital needs more difficult (stress test, asset quality review).

What will be the net effect of QE on the external value of the Euro in the short- to medium run? What immediately comes to mind is the following: if the ECB's QE should prove successful in increasing the value of Southern Eurozone's sovereign (and other purchased) bonds, this may lead to additional inflow of foreign capital stemming especially from emerging markets and, in turn, upward, instead of downward pressure on the Euro exchange rate. In Belke and Gros (2014), we therefore argue that the ECB should beware of unconventional impacts of its policy.

QE thus is, according to our view, a recipe of how not to fight the "ghost of deflation". As inflation in the Eurozone remains stubbornly low there is ever more pressure on the ECB 'to do something' to stimulate the economy and ward off the "ghost of deflation". Most of what is being proposed (and considered by the ECB) are variants of assets purchases whose aim is to lower interest rates. Short term interest rates are already close to zero for most assets of low risk (even the governments of Italy and Spain can now refinance themselves at less than $1 \%$ for maturities up to 2 years). The only rates which can still go down are thus longer term interest rates. But are even lower long term interest rates a solution (Belke and Gros, 2014)?

There are a couple of reasons to believe that lower rates might be counterproductive.

\subsection{Lower Interest Rates - Income Losses for Savers}

First of all, lower interest rates lower the returns for savers. A German household trying to increase his retirement income would have to save even more to achieve a certain target if interest rates were to go down. In the language of economists: it cannot be excluded that the income effect dominates the substitution effect of lower interest rates. And even lower interest rates force life insurers to limit their payouts. This is why a dose of QE leading to lower interest rates in Germany might not lead to stronger demand in Germany (Belke and Gros, 2014).

But do the most recent figures not have revealed that the level of domestic consumption is on a record level in Germany? That is true: real consumption finds itself on a record high but has been stagnating there since a couple of years. An operation QE would have the aim to have it increase significantly. We show, however, that also the contrary may be the case (Belke and Gros, 2014).

Of course, one could argue that for every saver there must be a borrower whose burden of debt goes down as interest rates decline. This is indeed true in a closed system. But Germany is a large net creditor and its economy thus loses income if interest rates go down. The debtors of Germany in the periphery of the Eurozone should of course then have a lower interest burden. But given that the peripheral economies are busily deleveraging their firms and households might just use this windfall for further debt reductions instead of increasing their expenditure. The Spanish households do not really profit from lower long-term rates because in the South the mortgage rates are indexed to very short-run interbank rates. Moreover, many over-indebted households and firms must first of all pay back their loans (deleveraging), before they can dare to think about new expenditures (Belke and Gros, 2014).

This is a specific Eurozone phenomenon. One reason why QE might have worked in the US is thus simply that the US is the world's biggest borrower and the various rounds of QE lowered considerably the interest burden on the entire economy. Foreigners hold about 7000 billion USD worth of US bonds (mostly Treasury paper). A reduction of the yield by 1 percentage point yields a net gain of about 0.5 percent of GDP and the investment income balance of the US had indeed improved since the start of QE by about 0.7 percent of GDP, although the net foreign investment position of the US has continued to deteriorate. For the US lower interest rates thus represent a considerable income gain. The opposite is the case of Germany, which has a considerable net creditor position, but whose investment balance has not improved much over the last years although the net creditor position has continued to balloon as the country continues to run large current account surpluses (Belke and Gros, 2014).. 
Seen on the whole, thus, ever lower interest rates may have a negative impact on demand in the Eurozone. At the start of European Monetary Union this was different, since at that time over-indebtedness was not prevalent on a large scale and house prices increased whereas they fall today (Belke and Gros, 2014).

\subsection{Increasing Real Estate Prices}

Another reason why lower interest rates are widely assumed to stimulate demand is via their impact on asset prices, especially house prices. Here again the US experience, where this mechanism is working, is misleading. The key problem lies again in Germany: house prices are indeed increasing, but this risks dampening, rather than fostering consumption demand. In Germany only a bit over $40 \%$ of households own their place of living. Most household just see rents increasing, which reduces their disposable income and lowers consumption. Since most housing is owned by financial institutions, such as insurance companies, the higher value of the housing stock could only appear on their balances sheets. However, under German accounting conventions, housing is not valued at market prices, but at historical cost. This is convenient for these financial institutions because it keeps their tax liabilities low. Higher house price thus cannot stimulate demand. On the contrary, for most German households an increase in house prices and rents represents a burden rather than boon (Belke and Gros, 2014).

Moreover, the German financial system does not allow those households who own their place of living to extract the higher value of their homes because of conservative loan to value ratios; and because most financial institutions would simply frown on any attempt to use higher house values for higher consumption which cannot be financed out of current income (Belke and Gros, 2014). (Note 7)

\subsection{Lower Interest Rates Stimulate Investment Demand Only to a Limited Extent}

Lower interest rates should lead to higher investment demand by firms. All economic models assume this. But all empirical studies find that interest rates have at best a marginal impact on investment and at any rate other factors easily swamp any marginal interest rate effect. These other factors relate to uncertainty about future policies (especially those dealing with a smooth exit from unconventional monetary policies and its side effects, see Belke, 2013) and market interventions such as minimum wages and linking sovereign bond yields to ECB interventions. In addition, enterprises in Europe tend to refinance themselves through bank loans whose maturity typically is short- to medium term. Hence, lower long-term rates yield little for firms (Belke and Gros, 2014).

All in all it appears that any QE or asset purchases might have a negative impact on demand in Germany and at best a marginal positive impact in the periphery. This implies that any move by the ECB to lower rates would make the intra area rebalancing even more difficult. The same applies to targeted facility for lending to SMEs. Any such scheme would be redundant in Germany. The key problem of the Eurozone is weak domestic demand in Germany and other Northern European surplus countries. This problem would only be worsened by the expansionary moves currently been advocated almost everywhere (Belke and Gros, 2014).

The ECB should thus resist the temptation to follow the standard approach of trying to drive down interest rates. What may have worked in the US or in the UK might be counterproductive in the Eurozone.

\subsection{QE's Exchange Rate Effect Will Not Stimulate the Business Cycle}

But also the exchange rate effect, i.e. the intended devaluation, does not speak in favour of business stimulation. It is often argued that the recovery of the Eurozone economy decisively hinges upon the prevention of a strong appreciation of the euro. And a depreciation which has been induced by lower interest rates should - according to the textbooks - in fact foster economic activity in the home country, dependent of course on the (expected) equilibrium exchange rate (Belke and Gros, 2014). But we feel legitimised to argue that the relation between the long-run interest rate and the exchange rate and, all the more so, the impact of the exchange rate on economic activity (hysteresis effects/path dependence) is rather loose Belke and Goecke, 2005 or Belke, Goecke and Guenther, 2013).

Even negative deposit rates may have a stronger impact on the Euro exchange rate than a QE programme (Belke and Gros, 2014), although Draghi (2014b) stated that “... we discussed the possibility of negative deposit rates, but our objective is maintaining price stability. We don't discuss policy measures for the effect they might have on the exchange rate; that is going to be determined by the marketplace".

It is not for nothing that a big part of the current discussion about the Fed's exit takes place in the framework of the so-called "interest rate puzzle" of the exchange rate: for a considerable time the USD/EUR exchange rate has not been corresponding with the expectations of a growing interest rate differential between both sides of the Atlantic. On the contrary, the Euro has been revaluating "unduly", i.e. against the consensus view prevailing at the start of the year which was that the US economic recovery would put upward pressure on the dollar and zat the low level of 
current and expected short-term interest rates initiated by the ECB's forward guidance was also likely to trigger a weakening of the euro. As an auxiliary ad hoc argument the markets which vehemently call for QE in the Eurozone contend that Euro appreciation in this case is, among others, due to the recent deleveraging of the ECB's balance sheet (see above). However, this argument is not at all corroborated up to now empirically in a robust fashion.

As shown earlier in this Paper, the exchange rate pain thresholds are - not only according to our own research - time variant and to a (for a currency union) surprisingly high degree also country-specific. But unfortunately for Germany, which is assigned a specific role as a growth locomotive in the Eurozone, the exchange rate elasticity of exports and, thus, also of the economic cycle is especially low. Hence, from this point of view the "locomotive" profits fewest of all from any devaluation of the euro.

\subsection{Impact of $Q E$ and Its Exchange Rate Effect Can Be Deflationary}

Seen on the whole, thus, QE or purchases of other bonds by the ECB should have a negative impact on aggregate demand in Germany and, if at all, lead to a marginally positive impact in the periphery of the Eurozone. The "rebalancing "of the Eurozone would be further compounded. The same is valid for targeted purchases of specific bundles of loans in order to promote the extension of credit to small and medium-sized enterprises (,targeted facility", "funding for lending" as adopted by the ECB in June 2014). Such a measure would be redundant in Germany. Still too weak domestic demand in Germany and other Northern European countries with current account surpluses remains the key problem of the Eurozone. The probability is large that exactly this problem will be exacerbated by the currently unison recommended expansionary monetary policy steps.

Hence, the ECB should overcome its temptation to fight the deflation danger via QE. What might have succeeded in the US and/or the UK will with a non-negligible probability not work in the Eurozone. Yes, the ECB should try to prevent general deflation but Quantitative Easing could make things even worse.

If our assertion pertains, $Q E$ should rather cause weaker demand and even less inflationary pressure - with the consequence that the $E C B$ will have to increase its dose of $Q E$. If that in turn leads to weaker demand, a deflationary spiral may emerge. This is all the more valid because (as argued above), if the ECB's QE should prove successful in increasing the value of Southern Eurozone's sovereign (and other purchased) bonds, this may lead to additional inflow of foreign capital stemming especially from emerging markets and, in turn, upward, instead of downward, pressure on the Euro exchange rate (Belke and Gros, 2014). (Note 8)

This kind of argument extends also to the ECB's envisaged asset-backed securities (ABS) purchases. When asked about the ABS purchases on which the ECB is currently intensifying its preparation and the possibility that, for example, US investors queue to buy such products, thereby provoking an upward pressure on the euro, Mario Draghi (2014) answered during the ECB June press conference: “... if this effort ... were to produce a product which is so attractive for the world, that means there will be a very sizeable financing inflow for the SMEs and the real economy. So that would be the greatest success. And for us in Europe it would certainly help to restore a one capital market and to fight fragmentation which is, in my view, one of the most important causes of the present crisis. I would value these benefits much more than the exchange rate". In cases of doubt, thus, the ECB will, according to Mario Draghi ("No, we don't have a trigger", (2014a)), not defend any implicit exchange rate target, an ideal starting point for speculators ready to test the ECB's exchange rate pain threshold.

\section{Conclusions}

The ECB will probably not be able to systematically affect the external value of the Euro - if at all - the effect may risk to exert an even deflationary impact. What might have worked in the US (QE and depreciating the dollar), may not work in the Eurozone. But even if the ECB would theoretically be able to lower the external value of the euro, it will not be successful in lowering structural rates of unemployment, the main impediment to escape a Japanese scenario. The best option under current circumstances would then be that the Fed will finally start its exit from unconventional monetary policies (for the exchange rate effects projected by the IMF see, for instance, (Belke, 2013)).

But also some general considerations apply. If a strong Euro is a clear expression of an increase in markets' confidence in Euro policies and improved business sentiments, why should the ECB take action against a "too strong euro"? The Euro will anyhow stay the safe haven currency with respect to the Ukraine (but less so with respect to the Iraq) crisis. (Note 9) This view is backed also by Mario Draghi (2014a): "We've been observing now since several months that what supports M3 in the presence of very weak, or weak credit flows, is actually inflows from outside. And some of these inflows from outside come from the regions that we've discussed. And they have the effect of keeping the euro strong". 
Taking Mario Draghi's statement "We don't discuss policy measures for the effect they might have on the exchange rate; that is going to be determined by the marketplace" (2014b) for granted, one may ask what other purposes do the permanent testimonies by ECB representatives on the big impact of the strong Euro on inflation figures in a low inflation environment serve then. Either the statement is not credible (Note 10) in view of all the political pressures exerted on the ECB or the ECB Governing Council really intends to abstain from unilaterally influencing the Euro exchange rate in view of the fact that the impact of the exchange rate on the Euro inflation varies strongly over time and it is not clear what the exchange rate compatible with the Eurozone's target inflation is. The latter interpretation would be really good news for the future of the Eurozone.

But this does, of course, not exclude concerted action to really move the forward markets. "You know that there is a G-20 statement that says that exchange rate matters are matters of common concern. And so we will have to reflect on this and see" (Draghi, 2014a). Seen on the whole, thus, the ECB is dealing adequately with the strong Euro. Hopefully it is not put under pressure by powerful interest groups to deviate from its current path.

\section{References}

Belke, A. (2013). Exit strategies and their impact on the Eurozone - A model based view. Briefing paper prepared for presentation at the Committee on Economic and Monetary Affairs of the European Parliament for the quarterly dialogue with the President of the European Central Bank, December, Brussels.

Belke, A., \& Goecke, M. (2005). Real options effects on employment: Does exchange rate uncertainty matter for aggregation? German Economic Review, 6(2), 185-203.

Belke, A., \& Gros, D. (2002). Designing EU-US monetary relations: the impact of exchange rate variability on labor markets on both sides of the Atlantic. The World Economy, 25(6), 789-813.

Belke, A., \& Gros, D. (2014). Kontraproduktive unkonventionelle Geldpolitik? oder: Wie das Gespenst der Deflation nicht $\mathrm{zu}$ vertreiben ist, Ökonomenstimme. Retrieved 24 April 2014, from http://www.oekonomenstimme.org/artikel/2014/04/kontraproduktive-unkonventionelle-geldpolitik-oder-wie-da s-gespenst-der-deflation-nicht-zu-vertreiben-ist/

Belke, A., \& Verheyen, F. (2014). The low interest rate environment, global liquidity spillovers and challenges for monetary policy ahead. Comparative Economic Studies, 56(2), 313-334.

Belke, A., Goecke, M., \& Guenther, M. (2013). Exchange rate bands of inaction and play-hysteresis in German exports - Sectoral evidence for some OECD destinations. Metroeconomica, 64(1), 152-179.

Belke, A., Herz, B., \& Vogel, L. (2006). Beyond Trade - Is Reform Effort Affected by the Exchange Rate Regime? A Panel Analysis for the World versus OECD Countries. Économie Internationale, 107, S. 29-58.

Belke, A., Koesters, W., Leschke, M., \& Polleit, T. Liquidity on the rise - Too much money chasing too few goods. Section 1.2: Exchange rate manipulation - an instrument to fight low growth?; ECB-Observer - Analyses of the Monetary Policy of the European System of Central Banks, No. 6, Februar, 2004, Frankfurt.

Draghi, M. (2014). Introductory statement to the press conference (with Q\&A); European Central Bank, Frankfurt/Main. $\quad$ Retrieved 5 June 2014, from http://www.ecb.europa.eu/press/pressconf/2014/html/is140605.en.html

Draghi, M. (2014a). Introductory statement to the press conference (with Q\&A), European Central Bank, Brussels. Retrieved 8 May, 2014 from http://www.ecb.europa.eu/press/pressconf/2014/html/is140508.en.html

Draghi, M. (2014a). Introductory statement to the press conference (with Q\&A). Frankfurt/Main. Retrieved 3 April 2014, from http://www.ecb.europa.eu/press/pressconf/2014/html/is140403.en.html

Eckert, D., \& Zschaepitz. H. (2014). Starke Währung macht Europäer kirre - Banker warnen: Hoher Wechselkurs droht Euro-Zone in eine Abwärtsspirale der Deflation zu stürzen. In Die Welt. Retrieved 25 March 2014, from http://www.welt.de/print/die_welt/finanzen/article126152213/Starke-Waehrung-macht-Europaeer-kirre.html

EEAG. (2014). The EEAG Report on the European Economy. Macroeconomic Outlook, CESifo, Munich, 15-53.

FAZ Für höhere Inflationsrate - EZB hat Berechnungen zu 1000-Milliarden-Geldspritze. Retrieved 5 April 2014, from http://www.faz.net/aktuell/wirtschaft/wirtschaftspolitik/fuer-hoehere-inflationsrate-ezb-hat-berechnungen-zu-10 00-milliarden-geldspritze-12880693.html 
Gros, D., Alcidi, C., Belke, A., Coutinho, L., \& Giovannini, A. (2014). State-of-play in implementing macroeconomic adjustment programmes in the Eurozone. Policy Note, Directorate General for Internal Policies, Economic Governance Support Unit, European Parliament, Brussels, February, und CEPS Working Document.

Jolly, D., Alderman, L., \& Bray, C. (2014). Five experts evaluate E.C.B.'s policy shift. New York Time. Retrieved 7 June 2014, from http://www.nytimes.com/2014/06/07/business/international/five-experts-evaluate-ecbs-policy-shift.html?_r=0

Krugman, P.R., Obstfeld, M., \& Melitz, M.J. (2012). International Economics - Theory \& Policy (9th ed.). Pearson, Boston et al..

Reinhart, C. M. (2012). The return of financial repression. CEPR Discussion Papers Series. 8947, Centre for Economic Policy Research, London.

Taylor, J.B. (2013). International monetary coordination and the great deviation. Paper prepared for the Session on International Policy Coordination, American Economic Association Annual Meetings, San Diego, California, January.

\section{Notes}

Note 1. For more details on local maxima of the dollar/euro exchange rate see [3].

Note 2. See [9] during the ECB's May Press Conference in Brussels: “... the strengthening of the exchange rate in the context of low inflation is cause for serious concern in the view of the Governing Council".

Note 3. Both should be very welcomed by the ECB and, hence, should not be counteracted by it.

Note 4. Deflation in the euro area itself has sometimes been even attached a certain probability of something like 20 percent, as measured among others by inflation-indexed bonds.

Note 5. See also Mario Draghi [9] in the ECB's Brussels press conference in May 2014 using exactly the same wording: «As I've said many times, it's not a policy target, but certainly is very important for price stability and for growth».

Note 6. See http://www.taipeitimes.com/News/biz/archives/2013/05/27/2003563249.

Note 7. See [4] for a robustness check of these arguments.

Note 8. For a supporting statement by the author see http://www.cnbc.com/id/101654170.

Note 9. See [9]: „The ESRB has a working group monitoring closely the developments from an economic viewpoint. Some national central banks have working groups also, watching closely what could be the consequences, especially the central banks of the countries that are the main trading partners with Russia and Ukraine".

Note 10. Questions from the audience "how confident are you to actually by your actions to drive the exchange rate?" and answers such as "they have an impact on our objective of price stability", both taken from [9], are revealing in this context. 